\title{
BIOLOGICAL CONTROL OF PHYTOPATHOGENIC FUNGI USING DIFFERENT EXTRACTS OF CHAETOMIUM CUPREUM
}

\author{
SHARMILA TIRUMALE*, NAZIR WANI
}

Department of Microbiology and Biotechnology, Jnanabharathi Campus, Bangalore University, Bengaluru - 560 056, Karnataka, India. Email: sharmilabub@gmail.com

Received: 21 April 2018, Revised and Accepted: 30 May 2018

\section{ABSTRACT}

Objective: This study evaluated the Chaetomium cupreum extracts as biocontrol agents against four plant pathogenic fungi (Cladosporium cladosporioides, Fusarium oxysporum, Phomopsis azadirachtae, and Rhizoctonia solani).

Method: The antifungal activity of n-butanol and ethyl acetate extracts of $C$. cupreum was evaluated against plant pathogenic fungi using food poison method.

Result: In n-butanol extract, the percentage inhibition of mycelial growth against $C$. cladosporoides was $88.3 \pm 0.1, F$. oxysporum was $59.4 \pm 0.2, R$. solani was $56.2 \pm 0.9$, and $P$. azadirachtae was $52.0 \pm 0.1$ at $0.25 \mathrm{mg} / \mathrm{ml}$, respectively. In ethyl acetate extract, the percentage inhibition of mycelial growth against $C$. cladosporoides was $86.0 \pm 0.5$, . oxysporum was $66.4 \pm 0.1, P$. azadirachtae was $55.2 \pm 0.9$, and $R$. solani was $52.0 \pm 0.1$ at $0.25 \mathrm{mg} / \mathrm{ml}$, respectively.

Conclusion: It was found that n-butanol extract is more effective than ethyl acetate extract of $C$. cupreum. Future studies will focus on the purification and characterization of compounds of $C$. cupreum and their biocontrol capacity with the mechanism for plant pathological applications.

Keywords: Chaetomium cupreum. Epipolythiodioxopiperazins. Cladosporium rot. Biopigments. Azaphilones.

(C) 2018 The Authors. Published by Innovare Academic Sciences Pvt Ltd. This is an open access article under the CC BY license (http://creativecommons. org/licenses/by/4. 0/) DOI: http://dx.doi.org/10.22159/ajpcr.2018.v11i9.26836

\section{INTRODUCTION}

The species of fungi such as Phomopsis sp., Cladosporium sp., Rhizoctonia sp., Aspergillus sp., Penicillium sp., and Fusarium sp. produce mycotoxins which cause heavy damage to fruits and vegetables during picking, transport and storage and thus affect their nutritional value and shelf life and make them unfit for human use [1]. Fungi also cause rot diseases in fruits and vegetables [2]. In India, neem tree is used for medicinal purposes. Ayurveda regards the tree as a "Sarva roga nivarini." The Phomopsis azadirachtae causes dieback disease in neem tree [3]. The fungus $P$. azadirachtae affects all parts of the neem tree. In the highly affected trees, it causes $100 \%$ loss of fruit productivity [4]. The field survey report indicates that all the trees in Mysore district in Karnataka were affected with P. azadirachtae [3]. The fungus Rhizoctonia solani causes leaf web blight to neem trees [4] and Fusarium oxysporum causes damping-off [5]. The fungus $R$. solani causes various diseases such as damping-off and wirestem in cabbage, cauliflower, and crucifer seedlings in the seedbed, bottom rot, head rot of older plants in the field, and root rot of rutabaga, horseradish, turnip, and radish. These diseases result in lower quality and product yield [6].

The fungus F. oxysporum $f$. sp lycopersici causes wilt disease in tomato crops worldwide [7]. Fusarium wilt is a banana disease is a caused in banana plants by F. oxysporum f. sp. cubense (Foc). During the harvesting stage, $C$. cladosporioides causes Blossom blight in strawberry in California, USA [8]. The C. cladosporioides also causes Cladosporium rot of red wine grapevines [9]. For controlling plant diseases, synthetic chemicals are used during transport and storage, but it is found that these synthetic chemicals have are toxic and non-biodegradable in nature and causes carcinogenicity, pathogenics to normal microorganisms, and pollutes the ground and soil environment [10]. Natural products, particularly microbial origin, are better alternatives and environmentally safe to control of plant diseases.

Chaetomium species are saprophytic ascomycetes, with Chaetomiaceae family. Since Kunze first established this genus in 1817, then 350
Chaetomium species have been described. The Chaetomium cupreum is a soil fungus exhibiting antagonism against various fungal phytopathogens [11]. In the present investigation, the ability of extracellular antifungal metabolites of $C$. cupreum was evaluated as biocontrol agents against plant pathogenic fungi (Cladosporium cladosporioides, F. oxysporum, P. azadirachtae, and R. Solani) were studied.

\section{METHODS}

\section{Isolation and identification of fungus}

The isolation of fungus C. cupreum was carried out from litter soil sample collected from the GKVK campus, Bengaluru, Karnataka, India, by Soumya et al., [12]. The strain with pigment production was selected and identified as C. cupreum-SS02 based on morphological and microscopic characteristics [13]. The morphological identity was confirmed by NFCCI, Agharkar Research Institute, Pune, India. To confirm the species, sequence analysis of the ITS region using universal primers (Forward primer, ITS 1 - TCCGTAGGTGAACCTGCGG, and Reverse primer, ITS 4 - TCCTCCGCTTATTGATATGC) was performed [14]. Nucleotide blast to the obtained sequence was performed in NCBI (www.ncbi.nlm.nih. gov/) using blast suite [15]. The C. cupreum culture was deposited in the National Fungal Culture Collection of India (NFCCI), Agharkar Research Institute, Pune, India, with accession number NFCCI 3117. The sequence was deposited in NCBI Genbank with accession number KF668034. The stock culture was maintained on a potato dextrose agar (PDA) slant at $4^{\circ} \mathrm{C}$.

\section{Fermentation and extraction}

In inoculum preparation, the fungus was grown on a PDA plate for 7-10 days and mycelial discs $(5 \mathrm{~mm})$ were transferred to $250 \mathrm{ml}$ Erlenmeyer flasks containing $100 \mathrm{ml}$ of potato dextrose broth and incubated at $26 \pm 2^{\circ} \mathrm{C}$ on a rotary shaker at $120 \mathrm{rpm}$ for 20 days to achieve the highest pigment production [16]. The culture of edible mushrooms produces high pigment production through submerged fermentation [17,18]. After 20 days of incubation, biomass was removed 
by filtration through Whatman No. 1 filter paper and the broth containing the extracellular metabolites was obtained. The extraction of pigments was carried out according to the method described by Lathadevi et al.[19]. The broth obtained was used for the extraction of the different compounds by separating funnel using different organic solvents from non-polar to polar (chloroform, ethyl acetate, n-butanol, and methanol) in the ratio of $1: 1$. The solvent layer was collected, filtered, and removed by evaporation under vacuum using rotary evaporator at $45^{\circ} \mathrm{C}$. The crude dried extract was obtained and stored at $4^{\circ} \mathrm{C}$ for future use.

\section{Antifungal activity of $C$. cupreum extract by Antifungal activity}

Fungal strains

Cladosporium cladosporoides, Fusarium oxysporum, Phomopsis azadirachtae and Rhizoctonia solani

\section{Antifungal activity by food poison method}

The antifungal activity of n-butanol and ethyl acetate of $C$. cupreum was evaluated against four plant pathogenic fungi using poisoned food method [20]. About $500 \mu \mathrm{l}$ from each of different concentrations $(0.25$, 0.5 , and $1.0 \mathrm{mg} / \mathrm{ml}$ ) of n-butanol and ethyl acetate extract of $C$. cupreum was added to PDA medium before solidification. A $6 \mathrm{~mm}$ mycelium disc of test fungi was inoculated on the PDA petri plate containing fungal extract. Then, inoculated plates were incubated at $25 \pm 2^{\circ} \mathrm{C}$ for 7 days. Three independent replicates were maintained for each treatment. Carbendazim was used as standard compound, and dimethyl sulfoxide without fungal extract was used as negative control. The diameter of the growth of fungus in PDA Petri plates was used as a control for the calculation of percentage inhibition of test fungi. After 7 days of incubation, the colony diameter was measured in millimeters. The percentage of mycelial growth inhibition was calculated using the following formula [21].

Inhibition $\%\left(\left(\mathrm{D}_{0}-\mathrm{D}_{1} / \mathrm{D}_{0}\right) \times 100\right.$.

Where $\mathrm{D}_{0}$ is the diameter of the mycelial mat in the control plate; $\mathrm{D}_{1}$ is the diameter of the mycelial mat in the test plate.

\section{Statistical analysis}

All the measurements were taken in triplicate and expressed as mean value \pm standard deviation. The data were analyzed for statistical significance using one-way analysis of variance (ANOVA) followed by Tukey's multiple comparison test with GraphPad Prism 6 software (GraphPad Software, Inc., USA). The probability values $\mathrm{p}<0.05$ were considered as statistically significant.

\section{RESULTS}

The antifungal activity of ethyl acetate and n-butanol extracts of C. cupreum was determined by employing food poison method. Among the four solvent extracts of $C$. cupreum, n-butanol and ethyl acetate extracts showed a concentration-dependent antifungal activity against phytopathogenic using food poison method.

Effect of n-butanol extract of $C$. cupreum on plant pathogenic fungi The antifungal activity of the n-butanol extract of $C$. cupreum against plant pathogenic fungi such as C. cladosporoides, F. oxysporum, P. azadirachtae, and R. solani is presented in Fig. 1. Our results have shown that antifungal activity increases by inhibiting the growth of the fungi with an increase in concentration. In n-butanol extract of $C$. cupreum, the percentage inhibition of mycelial growth against $C$. cladosporoides was $88.3 \pm 0.1, F$. oxysporum was $59.4 \pm 0.2, R$. solani was $56.2 \pm 0.9$, and P. azadirachtae was $52.0 \pm 0.1$ at $0.25 \mathrm{mg} / \mathrm{ml}$, respectively. Similarly, the percentage inhibition of mycelial growth against $C$. cladosporoides was $92.1 \pm 0.6, F$ oxysporum was $72.0 \pm 0.1, R$. solani was $70.8 \pm 0.5$, and P. azadirachtae was $67.4 \pm 0.5$ at $1.0 \mathrm{mg} / \mathrm{ml}$ concentration, respectively. The obtained results were compared with fungicide carbendazim (Fig. 1).

Effect of ethyl acetate of $C$. cupreum on plant pathogenic fungi The antifungal activity of ethyl acetate extract of $C$. cupreum against plant pathogenic fungi such as C. cladosporoides, F. oxysporum, P. azadirachtae, and R. solani is presented in Fig. 2. In ethyl acetate extract of $C$. cupreum, the percentage inhibition of mycelial growth against $C$. cladosporioides was $86.0 \pm 0.5, F$. oxysporum was $66.4 \pm 0.1$, P. azadirachtae was $55.2 \pm 0.9$, and $R$. solani was $52.0 \pm 0.1$ at $0.25 \mathrm{mg} / \mathrm{ml}$ respectively. The obtained results were compared with fungicide carbendazim. Similarly, the percentage inhibition of mycelial growth against $C$. cladosporioides was $91.0 \pm 0.1, F$. oxysporum was $80.0 \pm 0.2$, P. azadirachtae was $70.8 \pm 0.5$, and $R$. solani was $67.4 \pm 0.5$ at $1.0 \mathrm{mg} / \mathrm{ml}$, respectively. The obtained results were compared with fungicide carbendazim (Fig. 2 and Fig. 3).

\section{DISCUSSION}

The pure fungus culture was identified based on morphological and microscopic characteristics and named as C. cupreum. The organism C. cupreum was identified based on morphological and microscopic characteristics and molecular analysis and named as C. cupreum. The fungus $C$. cupreum fungus produces extracellular pigments in the fermented broth. The extraction of pigments was carried out by different solvents from non-polar to polar. The results of the present study have shown the significant antifungal activity of $C$. cupreum extracts against the phytopathogenic fungi. Among the four phytopathogenic fungi (C. cladosporioides, F. oxysporum, P. azadirachtae, and R. solani), C. cladosporoides was the most susceptible to both the n-butanol and ethyl acetate extract of $C$. cupreum. From the results, it was observed that growth of fungal mycelium decreases with the increase in the concentration of $C$. cupreum extracts.

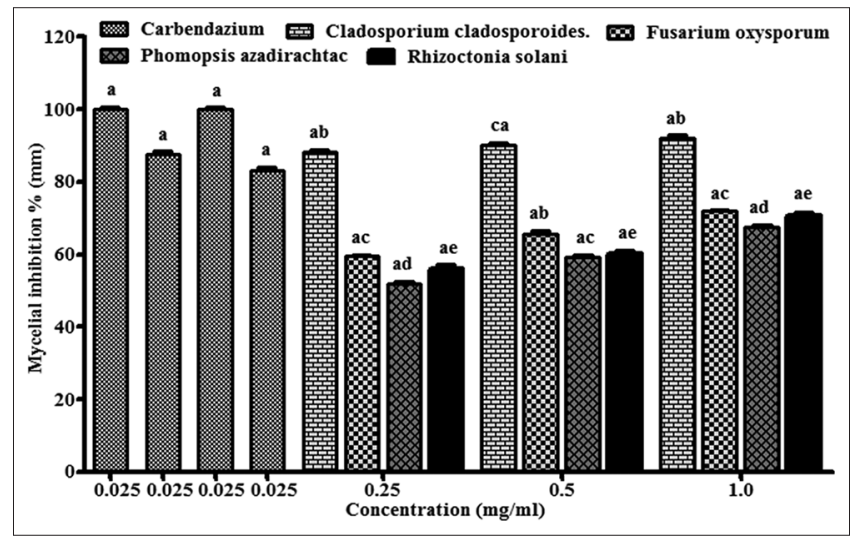

Fig. 1: Effect of antifungal activity of $\mathbf{n}$-butanol extract of Chaetomium cupreum by food poison method.

(Standard - carbendazim, Control - Dimethyl sulfoxide). Bars in each column with common letters indicate significant difference $(p<0.05)$ according to Tukey's multiple comparison test. Experimental results are expressed as mean $\pm S D(n=3)$

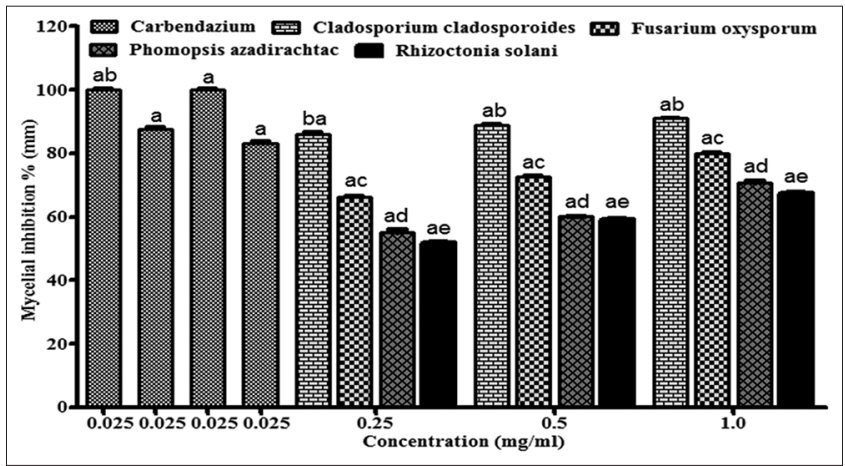

Fig. 2: Effect of antifungal activity of ethyl acetate extract of Chaetomium cupreum by food poison method. (Positive control - carbendazium, Negative control - Dimethyl sulfoxide). Bars in each column with common letters indicate significant difference $(p<0.05)$ according to Dunnett's multiple comparison test. Experimental results are expressed as mean $\pm S D(n=3)$ 
In n-butanol extract (Fig. 1), the percentage of mycelium growth inhibition was high in C. cladosporoides $(88.30 \%)$ followed by F. oxysporum (59.40\%) and R. Solani (56.20\%), whereas lowest in P. azadirachtae $(52 \%)$ at $0.25 \mathrm{mg} / \mathrm{ml}$. At higher concentration, the percentage of mycelium growth inhibition increases in $C$. cladosporoides (92.10\%) followed by F. oxysporum $(72 \%)$ and R. Solani $(70.80 \%)$, whereas lowest in $P$. azadirachtae $(67.40 \%)$ at $0.1 \mathrm{mg} / \mathrm{ml}$. Whereas in reference standard carbendazim, the percentage of mycelium growth inhibition was highest in $C$. cladosporoides and $P$. azadirachtae (100\%), followed by F. oxysporum $(87.70 \%)$ and R. Solani $(83 \%)$ at $0.025 \mathrm{mg} / \mathrm{ml}$. The percentage of mycelium growth inhibition of n-butanol extract of $C$. cupreum and standard carbendazim decreased in the order of carbendazim $>C$. cladosporioides $>F$. oxysporum $>R$. solani $>$ P. azadirachtae. The statistical significance using ANOVA followed by Tukey's multiple comparison test was performed, and probability values $\mathrm{p}<0.05$ were considered as statistically significant. For statistical analysis, antifungal activity of n-butanol extract of $C$. cupreum was compared to the standard carbendazim, and it was observed that all phytopathogenic fungi except C. cladosporoides (carbendazim vs. C. cladosporoides $\mathrm{p}>0.05$ ) showed significant difference (carbendazim vs.. F. Oxysporum $\mathrm{p}<0.05$, carbendazim vs. $P$. azadirachtac $\mathrm{p}<0.05$, and carbendazim vs. $R$. solani $\mathrm{p}<0.05$ ) as shown in Table 1 . In ethyl acetate extract (Fig. 2), the percentage of mycelium growth inhibition was highest in C. cladosporoides (86\%), followed by F. oxysporum $(66.40 \%)$ and $P$. azadirachtae (55.20\%), whereas lowest in R. Solani $(52 \%)$ at $0.25 \mathrm{mg} / \mathrm{ml}$. At higher concentration, the percentage of mycelium growth inhibition increases in C. cladosporoides (91\%) followed by F. oxysporum (80\%) and P. azadirachtae (70.80\%), whereas lowest in $R$. Solani $(67.40 \%)$ at $0.1 \mathrm{mg} / \mathrm{ml}$. Whereas in reference standard carbendazim, the percentage of mycelium growth inhibition was highest in C. cladosporoides and P. azadirachtae (100\%) followed by $F$. oxysporum $(87.70 \%)$ and $R$. solani $(83 \%)$ at $0.025 \mathrm{mg} / \mathrm{ml}$. The percentage of mycelium growth inhibition of ethyl acetate extract of $C$. cupreum and standard carbendazim decreased in the order of carbendazim $>C$. cladosporoides $>F$. oxysporum $>$ P. azadirachtae $>$ $R$. solani. The statistical significance using one-way ANOVA followed by Tukey's multiple comparison test was performed and probability values $\mathrm{p}<0.05$ was considered as statistically significant. For statistical analysis, antifungal activity of ethyl acetate extract of $C$. cupreum was compared to the standard carbendazim, and it was observed that all phytopathogenic fungi except $C$. cladosporoides (carbendazim vs. $C$. cladosporoides $\mathrm{p}>0.05$ ) showed significant difference (Carbendazim vs. F. oxysporum $\mathrm{p}<0.05$, carbendazim vs. $P$. azadirachtac $\mathrm{p}<0.05$, and carbendazim vs. $R$. solani $\mathrm{p}<0.05$ ) as shown in Table 2 .

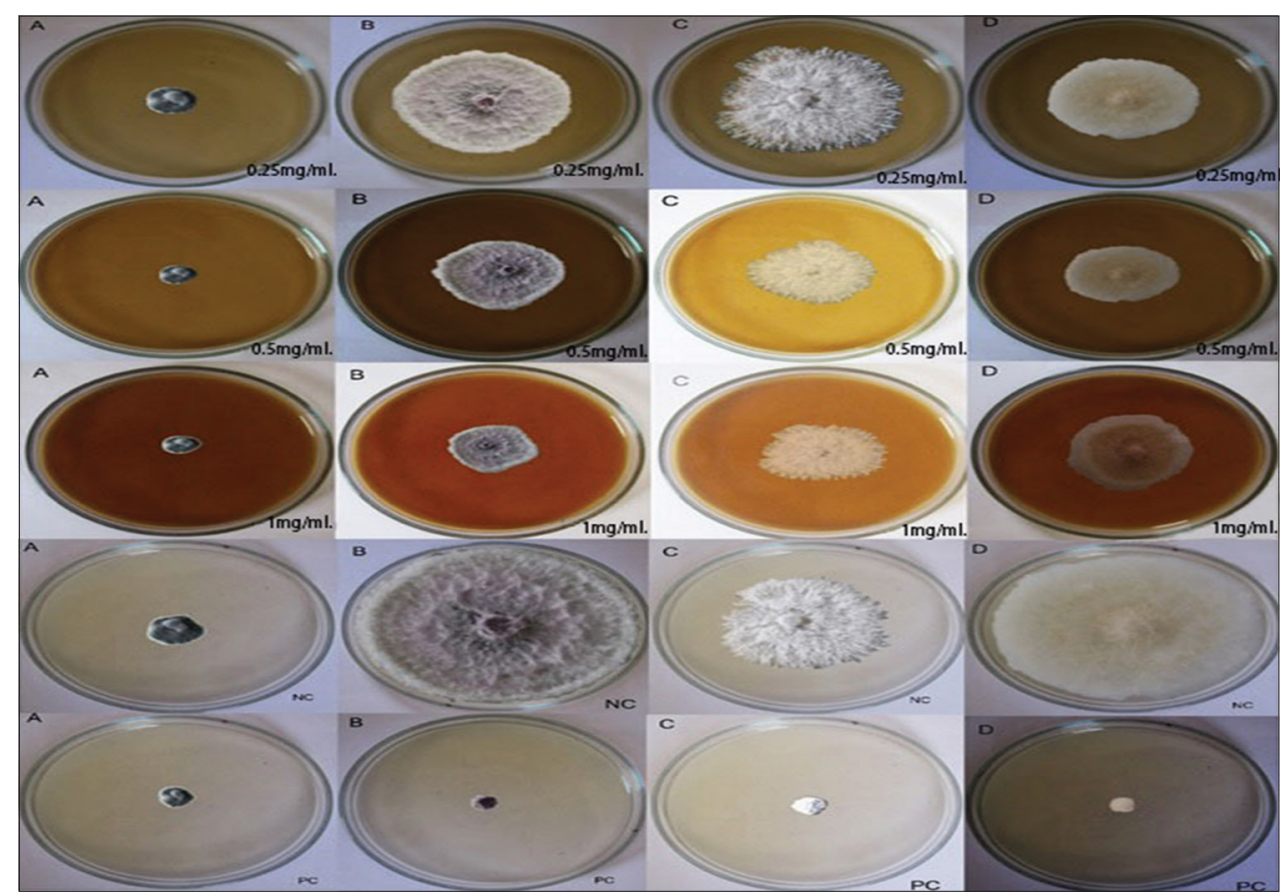

Fig. 3: Antifungal activity by of n-butanol extract of C. cupreum(A) Cladosporium cladosporioides, (B) Fusarium oxysporum, (C) Phomopsis azadirachtae, (D) Rhizoctonia solani

Table 1: Tukey's multiple comparison test for n-butanol extract of $C$. cupreum on phytopathogenic fungi and its comparison with carbendazim

\begin{tabular}{|c|c|c|c|c|c|}
\hline Tukey's multiple comparison test & Mean difference & $\mathbf{q}$ & Significant $(p<0.05)$ & Summary & $95 \%$ CI of diff \\
\hline Carbendazim versus $C$. cladosporioides & 2.542 & 0.6683 & No & ns & $-14.85-19.94$ \\
\hline Carbendazim versus F. oxysporum & 27.04 & 7.111 & Yes & $* *$ & $9.647-44.44$ \\
\hline Carbendazim versus $P$. azadirachtae & 33.18 & 8.724 & Yes & $* * *$ & $15.78-50.57$ \\
\hline Carbendazim versus $R$. solani & 30.31 & 7.970 & Yes & $* *$ & $12.91-47.70$ \\
\hline C. cladosporioides versus $F$. oxysporum & 24.50 & 6.026 & Yes & $* *$ & $5.905-43.10$ \\
\hline C. cladosporioides versus $P$. azadirachtae & 30.63 & 7.535 & Yes & $* *$ & $12.04-49.23$ \\
\hline C. cladosporioides versus $R$. solani & 27.77 & 6.830 & Yes & $* *$ & $9.171-46.36$ \\
\hline F. oxysporum versus $R$. solani & 3.267 & 0.8035 & No & ns & $-15.33-21.86$ \\
\hline P. azadirachtae versus $R$. solani & -2.867 & 0.7051 & No & ns & $-21.46-15.73$ \\
\hline
\end{tabular}

The probability symbol ${ }^{*}$ indicates significant difference $(\mathrm{p}<0.05) .\left({ }^{* * *} \mathrm{p}<0.001,{ }^{* *} \mathrm{p}<0.01,{ }^{*} \mathrm{p}<0.1, \mathrm{p}<0.05\right.$ and NS: non-significant). The results are expressed as the mean of three measurements \pm standard deviation. The data were analyzed for statistical significance using ANOVA followed by Tukey's multiple comparison test. C. cladosporioides: Cladosporium cladosporioides, F. oxysporum: Fusarium oxysporum, P. azadirachtae: Phomopsis azadirachtae, R. solani: Rhizoctonia solani 
Table 2: Tukey's multiple comparison test for ethyl acetate extract of $C$. cupreum on phytopathogenic fungi and its comparison with carbendazim

\begin{tabular}{|c|c|c|c|c|c|}
\hline Tukey's multiple comparison test & Mean difference & $\mathbf{q}$ & Significant $(\mathrm{p}<0.05)$ & Summary & $95 \%$ CI of diff \\
\hline Carbendazim versus $C$. cladosporioides & 4.008 & 1.025 & No & ns & $-13.89-21.90$ \\
\hline Carbendazim versus F. oxysporum & 19.71 & 5.038 & Yes & $*$ & $1.814-37.60$ \\
\hline Carbendazim versus $P$. azadirachtae & 30.64 & 7.832 & Yes & $* *$ & $12.75-48.54$ \\
\hline Carbendazim versus $R$. solani & 33.18 & 8.480 & Yes & $* * *$ & $15.28-51.07$ \\
\hline C. cladosporioides versus F. oxysporum & 15.70 & 3.754 & No & ns & $-3.430-34.83$ \\
\hline C. cladosporioides versus $P$ azadirachtae & 26.63 & 6.368 & Yes & $* *$ & $7.503-45.76$ \\
\hline C. cladosporioides versus $R$. solani & 29.17 & 6.974 & Yes & $* *$ & $10.04-48.30$ \\
\hline F. oxysporum versus $R$. solani & 13.47 & 3.220 & No & ns & $-5.664-32.60$ \\
\hline P. azadirachtae versus $R$. solani & 2.533 & 0.6057 & No & Ns & $-16.60-21.66$ \\
\hline
\end{tabular}

The probability symbol* indicates significant difference ( $\mathrm{p}<0.05)$. $\left({ }^{* * *} \mathrm{p}<0.001,{ }^{* *} \mathrm{p}<0.01,{ }^{*} \mathrm{p}<0.1, \mathrm{P}<0.05\right.$ and NS: non-significant). The results are expressed as the mean of three measurements \pm standard deviation. The data were analyzed for statistical significance using ANOVA followed by Tukey's multiple comparison test. C. cladosporioides: Cladosporium cladosporioides, F. oxysporum: Fusarium oxysporum, P. azadirachtae: Phomopsis azadirachtae, R. solani: Rhizoctonia solani. CI: Confidence interval

It was observed that the $C$. cupreum extracts inhibited the growth of all phytopathogenic fungi. This antifungal activity may due to the different phytochemicals present in the C. cupreum extract. These results are of great importance, particularly against phytopathogenic fungi, which are responsible for heavy crop loss every year [22]. These results have shown that the ethyl acetate and n-butanol extracts of $C$. cupreum exhibit higher antifungal activity as compared to the crude extracts of $F$. oxysporum and Fusarium poae, isolated from Ophiopogon japonicus, investigated for their inhibition against several phytopathogens [23]. Furthermore, the crude extracts of $C$. cupreum exhibit higher antifungal activities as compared to the water and ethanol extracts from mushroom samples conducted against three plant pathogenic fungi [24]. The extracts of C. cupreum have shown higher antifungal activity as compared to the extracellular antifungal metabolites of actinomycetes against Rhizopus stolonifer, Aspergillus flavus, F. oxysporum, and Alternaria sp. [25]. The C. cupreum extracts exhibit higher antifungal activity as compared to methanolic extract of Abutilon theophrasti against Penicillium spp. [26]. The three new azaphilones such as rotiorinols A-C (1-3), with two new stereoisomers, (-)-rotiorin (4) and epiisochromophilone II (5), and a known compound, rubrorotiorin (6) were isolated from the fungus C. cupreum CC3003. The compounds 1, 3, 4, and 6 showed antifungal activity against Candida albicans with IC $_{50}$ values of $10.5,16.7,24.3$, and $0.6 \mu \mathrm{g} / \mathrm{ml}$ [27]. The commercially available broad-spectrum fungicide, Ketomium ${ }^{\circledR}$, which is used in crop diseases control, was developed from Chaetomium species [28]. By observing these promising biological activities and diverse structural characters, azaphilones have opened a new subject for research. The present study revealed that $C$. cupreum extracts have significant potential for antifungal applications. This antifungal potential of $C$. cupreum is due to the presence of different types of phytochemicals.

\section{CONCLUSION}

The biological control with antagonistic microorganisms is a suitable and easy method for plant protection. The $C$. cupreum is producing extracellular metabolites which are easily extracted as compared to other fungi and mushrooms. Thus, it was found that n-butanol extract and ethyl acetate extract of $C$. cupreum showed significant antifungal activity due to the presence of phytochemicals. The flavonoids play an important role in biological activity [29]. The obtained results clearly confirmed that both the n-butanol and ethyl acetate extracts of the C. cupreum contain different phytochemicals particularly flavonoids that can be used in plant protection after their purification and characterization.

\section{FUNDING}

The authors are grateful to UGC (University Grants Commission), New Delhi, Governmet of India, for UGC-MRP (No-43-474/2014SR) Grants for financial support and also to the Head, Department of Microbiology and Biotechnology (MB and BT), Bangalore University,
Bengaluru (BUB), for the use of laboratory facilities.

\section{DISCLOSURE STATEMENT}

The author declares no conflict of interest.

\section{AUTHOR'S CONTRIBUTIONS}

NAW carried out all the assays, analysis, and interpretation of results and wrote the initial manuscript. ST was responsible for the idea of research and interpretation of the results and edited the manuscript.

\section{REFERENCES}

1. Galvano F, Piva A, Ritieni A, Galvano G. Dietary strategies to counteract the effect of mycotoxins: A review. J Food Protect 2001;64:120-31.

2. Ali S, Rivera VV, Secor GA. First report of Fusarium graminearum causing dry rot of potato in North Dakota. Plant Dis 2005;89:105.

3. Sateesh MK. Microbiological investigations on Die-Back Disease of Neem (Azadirachta indica A. Juss.). Ph.D. Thesis. University of Mysore. Mysore, India; 1998.

4. Bhat SS, Sateesh MK, Devaki NS. A new destructive disease of neem (Azadirachta indica) incited by Phomopsis azadirachtae. Curr Sci 1998;74:17-9.

5. Tewari DN. Monograph of neem (Azadirachta indica A. Juss.). Dehra Dun, India: International Book Distributors; 1992.

6. Babadoost M. Rhizoctonia Disease of Cabbage and Related Crops (Report on Plant Disease). Department of Crop Sciences, University of Illinois at Urbana-Champaign; 1998.

7. Reis A, Boitetux LS. Outbreak of Fusarium oxysporum f. sp. lycopersici race 3 in commercial fresh-market tomato fields in Rio de Janeiro State, Brazil. Horticu Bras 2007;25:451-4.

8. Gubler WD, Feliciano AJ, Bordas AC, Civerolo EC, Melvin JA, Welch NC. First report of blossom blight of strawberry caused by Xanthomonas fragariae and Cladosporium cladosporioides in California. Plant Dis 1999;83:400.

9. Latorre BA, Briceño EX, Torres R. Increase in Cladosporium spp. populations and rot of wine grapes associated with leaf removal. Crop Prot 2011;30:52-6.

10. Pimentel D, Levitan L. Pesticides: Amounts applied and amounts reaching pests. Bioscience 1986;36:86-91.

11. Mao BZ, Huang C, Yang GM, Chen YZ. Separation and determination of the bioactivity of oosporein from Chaetomium cupreum. Afr J Biotechnol 2010;9:5955-61.

12. Soumya K, Swathi L, Sreelatha GL, Sharmila T. Light influences Pigment, biomass and morphology in Chaetomium cupreum - SS02-a photoresponse study. Int J Curr Microbiol App Sci 2014;3:53-64.

13. Kim JY, Sun YL, Hye SC. Molecular and morphological identification of fungal species isolated from rice meju. Food Sci Biotechnol 2013;22:721-8.

14. White TJ, Bruns T, Lee S, Taylor J. Amplification and Direct Sequencing of Fungal Ribosomal RNA Genes for Phylogenetics. In PCR Protocols: A Guide to Methods and Applications; 1990. p. 315-22.

15. Altschul SF, Madden TL, Schäffer AA, Zhang J, Zhang Z, Miller W, et al. Gapped BLAST and PSI-BLAST: A new generation of protein 
database search programs. Nucleic Acids Res 1997;25:3389-402.

16. Kang B, Zhang X, Wu Z, Qi H, Wang Z. Solubilization capacity of nonionic surfactant micelles exhibiting strong influence on export of intracellular pigments in Monascus fermentation. Microb Biotechnol 2013;6:540-50.

17. Park JP, Kim SW, Hwang HJ, Yun JW. Optimization of submerged culture conditions for the mycelial growth and exo-biopolymer production by Cordyceps militaris. Lett Appl Microbiol 2001;32:1-6.

18. Kim SW, Hwang HJ, Xu CP, Na YS, Song SK, Yun JW. Influence of nutrition conditions on the mycelial growth and exopolysaccharide production in Paecilomyces sinclairii. Lett Appl Microbiol 2002;34:389-93

19. Lathadevi KC, Chandi CR, Bapuji M, Gulnihal O. Pigment production from a mangrove penicillium. Afr J Biotechnol 2014;13:2668-74.

20. Amadioha AC. Controlling rice blast in vitro and in vivo with extracts of Azadirachta indica. Crop Prot 2000;19:287-90.

21. Das K, Tiwari RKS, Srivastava DK. Techniques for evaluation of medicinal plant products as antimicrobial agent: Current methods and future trends. J Med Plant Res 2010;4:104-11.

22. Dong J. New nematicidal azaphilones from the aquatic fungus Pseudohalonectria adversaria. Microbiol Lett 2006;264:65-79.

23. Liu CH, Liu TT, Yuan FF, Gu YC. Isolating endophytic fungi from evergreen plants and determining their antifungal activities. Afr J Microbiol Res 2010;4:2243-8.

24. Ahmed I, Chandana J, Geon WL, Tae SL. Antibacterial and antifungal activities of Stereum ostrea, an inedible wild mushroom. Mycobiol 2007:4:210-4

25. Harpreet S, Leena P. Antifungal activity of extracts obtained from Actinomycetes. J Yeast Fungal Res 2010;1:197-200.

26. Musheerul H, Huma H, Nasreen K, Zargar M, Reyaz AM. Evaluation of root and leaf of abutilon Theophrasti medik for antifungal activity. Asian J Pharm Clin Res 2016;9:75-7.

27. Kanokmedhakul S, Kanokmedhakul K, Nasomajai P, Louangsyouphanh $\mathrm{S}$, Soytong $\mathrm{K}$, Isobe $\mathrm{M}$, et al. Antifungal azaphilones from the fungus Chaetomium cupreum CC3003. J Nat Prod 2006;69:891-5.

28. Arunachalam M, Mohan RM, Mohan N, Mahadevan A. Biodegradation of catechin. Proc Indian Natn Sci Acad B 2003;69:353-70

29. Slimani A, Moussaoui A, Laazouni H. Phytochemical screening, contribution to the study of the antifungal effect of flavonoids from different parts of Ziziphus lotus of South-West Algeria. Asian J Pharm Clin Res 2017;10:13-6. 